\title{
Synthesis, Characterization and Theoretical Calculations of Novel Five Membered Rings Containing Phosphorus and Arsenic Atoms
}

\author{
Willian R. Rocha ${ }^{*, \#, a}$, Leopoldo W. M. Duarte ${ }^{b}$,Wagner B. De Almeida ${ }^{b}$ and Vinicius Caliman $^{b}$ \\ ${ }^{a}$ Departamento de Química, ICE, Universidade Federal de Juiz de Fora, UFJF, 36036-330 Juiz de Fora - MG, Brazil \\ ${ }^{b}$ Departamento de Química, ICEx, Universidade Federal de Minas Gerais, UFMG, 31270-901 Belo Horizonte - MG, \\ Brazil
}

\begin{abstract}
A síntese de dois novos arsadifosfóis de fórmula $\left(\mathrm{AsP}_{2} \mathrm{C}_{2} \mathrm{Bu}_{2}^{\mathrm{t}}\right) \mathrm{CH}\left(\mathrm{SiMe}_{3}\right)_{2}$, a partir dos anéis aniônicos 4-arsa-1,2-difosfaciclopentadienil e 2-arsa-1,4-difosfaciclopentadienil é reportada, junto com suas caracterizações utilizando RMN de ${ }^{31} \mathrm{P}$. Cálculos ab initio no nível MP2/6-31G(d) de teoria foram realizados para se investigar as barreiras de inversão piramidal, estabilidade relativa e o caráter aromático de todos os possíveis isômeros dos arsadifosfóis, em fase gasosa. A distribuição termodinâmica dos isômeros está em completo acordo com os resultados experimentais. O caráter de aromaticidade obtido para os três isômeros contendo um fósforo $\mathrm{sp}^{3}$ é maior quando comparado com o 1,2,4-trifosfol, sintetizado previamente. Os efeitos dos grupos substituintes volumosos sobre a aromaticidade e as barreiras de inversão piramidal são também discutidos.
\end{abstract}

The synthesis of two new arsadiphospholes of formula $\left(\mathrm{AsP}_{2} \mathrm{C}_{2} \mathrm{Bu}_{2}^{\mathrm{t}}\right) \mathrm{CH}\left(\mathrm{SiMe}_{3}\right)_{2}$, from 4-arsa1,2-diphosphacyclopentadienyl and 2-arsa-1,4-diphosphacyclopentadienyl ring anions are reported together with their characterization by ${ }^{31} \mathrm{P} \mathrm{NMR}$. A b initio calculations at the MP2/6-31G(d) level of theory were carried out to investigate the energy barrier for pyramidal inversion about the pyramidal $\mathrm{P}$ and As atoms, relative stability and aromaticity character of all possible isomers in the gas phase. The thermodynamic isomers distribution is in agreement with the experimental results. The inversion barrier at the $\mathrm{sp}^{3}$ phosphorus compared to the inversion barrier found for the arsenic atom is low. This fact is directly related with the aromaticity of the rings and shows the preference of the side group for the phosphorus atom, which leads to a more aromatic ring structure. The aromaticity character found for three isomers containing a $\mathrm{sp}^{3}$-phosphorus is greater if compared with that of 1,2,4-triphosphole synthesized previously. The effects of bulky R substituents on the aromaticity and on the energy barrier for pyramidal inversion are also discussed.

Keywords: arsadiphospholes, synthesis, ${ }^{31} \mathrm{P}$ NMR, aromaticity, ab initio calculations

\section{Introduction}

Five membered rings containing phosphorus atoms have been synthesized since $1959 .{ }^{1}$ However, nearly $75 \%$ of all known rings of this kind were prepared in the last ten years, showing the importance that chemists are giving to this type of compounds. Phosphole (Figure 1), is known to be a nonplanar, nonaromatic molecule..$^{2-5}$ This behavior is attributed to the pyramidal character at phosphorus. ${ }^{6}$ This

\footnotetext{
* e-mail: wrocha@npd.ufpe.br

\# Present Address: Departamento de Química Fundamental - CCEN, Universidade Federal de Pernambuco, Avenida Prof. Luiz Freire s/ n, Cidade Universitária, 50740-901 Recife - PE, Brazil
}

class of compounds is of particular interest in coordination chemistry due to its ability to act in several different coordination modes. For instance, phosphole can act as a two electron donor, when bonding occurs to a metal by donation of the phosphorus lone pair only; four electron

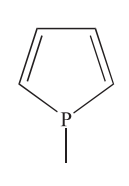

Phosphole

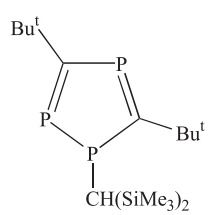

1

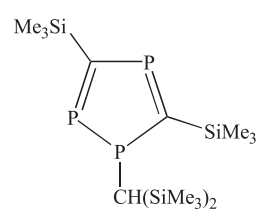

2
Figure 1. Chemical structures of phosphole, 1-[bis(trimethylsilyl) methyl]-3-5-di-tert-butyl-1,2,4-triphosphole (1) and 1[bis(trimethylsilyl)methyl]-3,5-trimethylsilyl-1,2,4-triphosphole (2). 
donor, when the diene system is coordinated only and six electron donor when the diene system is bound to one metal and the phosphorus behaves as a two electron donor to a second metal. All these coordination modes have been reviewed in the literature..$^{2-4}$

Theoretical calculations ${ }^{7-9}$ have shown that increasing the number of phosphorus atoms in the ring structure of phosphole leads to a decrease in the pyramidal character of the $\mathrm{sp}^{3}$ phosphorus, giving rise to a planar phosphole structure. These calculations also showed that the ring planarity is directly related to the electronic delocalization (or aromaticity) and a planar ring is predicted to be strongly aromatic by means of theoretical calculations.

The synthesis of the first triphosphole, 1[bis(trimethylsilyl)methyl]-3-5-di-tert-butyl-1,2,4triphosphole (1) (Figure 1) was reported ${ }^{10}$ by one of us in 1995. This molecule showed some planarity, with the sum of bond angles around the $\mathrm{sp}^{3}$ phosphorus atom equal to $342^{\circ}$, which is considerably greater than the analogous mono and diphospholes (302 and $320^{\circ}$, respectively). Using the same synthetic route, Cloke et al. ${ }^{11}$ recently published the synthesis of a triphosphole, 1[bis(trimethylsilyl)methyl]-3,5-trimethylsilyl-1,2,4triphosphole (2) containing a planar ring structure, with $\sum_{\text {angles }}$ around the $\sigma^{3}$ phosphorus. Compound $\mathbf{2}$ is not only planar but also shows aromatic character. The Bird aromaticity index ${ }^{12}$ for 2 was found to be 84 , which is significantly greater than 56 found for $\mathbf{1}$.

In this work we present the synthesis of two new arsadiphospholes, which are five membered rings containing 2 phosphorus, 2 carbons and an arsenic atom forming the ring structure. Ab initio molecular orbital calculations were also performed to evaluate the relative stability, inversion barrier and aromaticity character of the five possible isomers of arsadiphosphole. The effect of bulky substituents on the aromaticity and energy barrier to pyramidal inversion is also discussed.

\section{Results and Discussion}

The synthetic route used for the syntheses of both triphospholes reported so far (compounds $\mathbf{1}$ and 2), involved the coupling reaction between the anionic rings $\left(\mathrm{P}_{3} \mathrm{C}_{2} \mathrm{Bu}_{2}^{\mathrm{t}}\right)^{-}$and $\left[\mathrm{P}_{3} \mathrm{C}_{2}\left(\mathrm{SiMe}_{3}\right)_{2}\right]^{-}$and a bulky $\mathrm{R}$ group $[\mathrm{R}=$ $\left.-\mathrm{CH}\left(\mathrm{SiMe}_{3}\right)_{2}\right]$. The synthesis of the anionic rings 4-arsa1,2-diphosphacyclopentadienyl (3) and 2-arsa-1,4diphosphacyclopentadienyl (4) reported by Nixon and coworkers, ${ }^{13}$ prompted us to synthesize two new arsadiphospholes using the same bulky side group described above. The mixture containing both rings $\mathbf{3}$ and 4, which was obtained from $\mathrm{SiMe}_{3} \mathrm{P}=\mathrm{C}\left(\mathrm{Bu}^{\mathrm{t}}\right) \mathrm{OSiMe}_{3}$ and
$\mathrm{LiAs}\left(\mathrm{SiMe}_{3}\right)_{2}$, reacts with $\mathrm{BrCH}\left(\mathrm{SiMe}_{3}\right)_{2}$ in dimethoxyethane as shown in Figure 2. The reaction of $\mathrm{BrCH}\left(\mathrm{SiMe}_{3}\right)_{2}$ with the anionic ring $\mathbf{3}$ may generate two isomers $\mathbf{5}$ and $\mathbf{7}$ (route A in Figure 2). The former is obtained through the bonding of the $\mathrm{R}$ group to the phosphorus atom and in the later, the $\mathrm{R}$ group bonds to the arsenic atom. The reaction of $\mathrm{BrCH}\left(\mathrm{SiMe}_{3}\right)_{2}$ with the anionic ring 4 in route $\mathrm{B}$, may produce compounds $\mathbf{6 , 8}$ and $\mathbf{9}$, generated from the bonding of the bulky side group to the two unequivalent phosphorus atoms and to the arsenic atom, respectively. In the synthetic procedure employed here (Figure 2), we found that the mixture containing both rings $\mathbf{3}$ and $\mathbf{4}$ reacts with $\mathrm{BrCH}\left(\mathrm{SiMe}_{3}\right)_{2}$ to give, exclusively, the two new arsadiphospholes $\mathbf{5}$ and $\mathbf{6}$, which have both been characterized by ${ }^{31} \mathrm{P}$ NMR spectroscopy. As expected, in compound $\mathbf{5}$ the $\mathrm{R}$ group is bonded to the ring via one of the two phosphorus bonded together, which are the less hindered atoms. Compound $\mathbf{6}$ showed the $\mathrm{R}$ group attached to the ring via the phosphorus bonded directly to the arsenic atom.

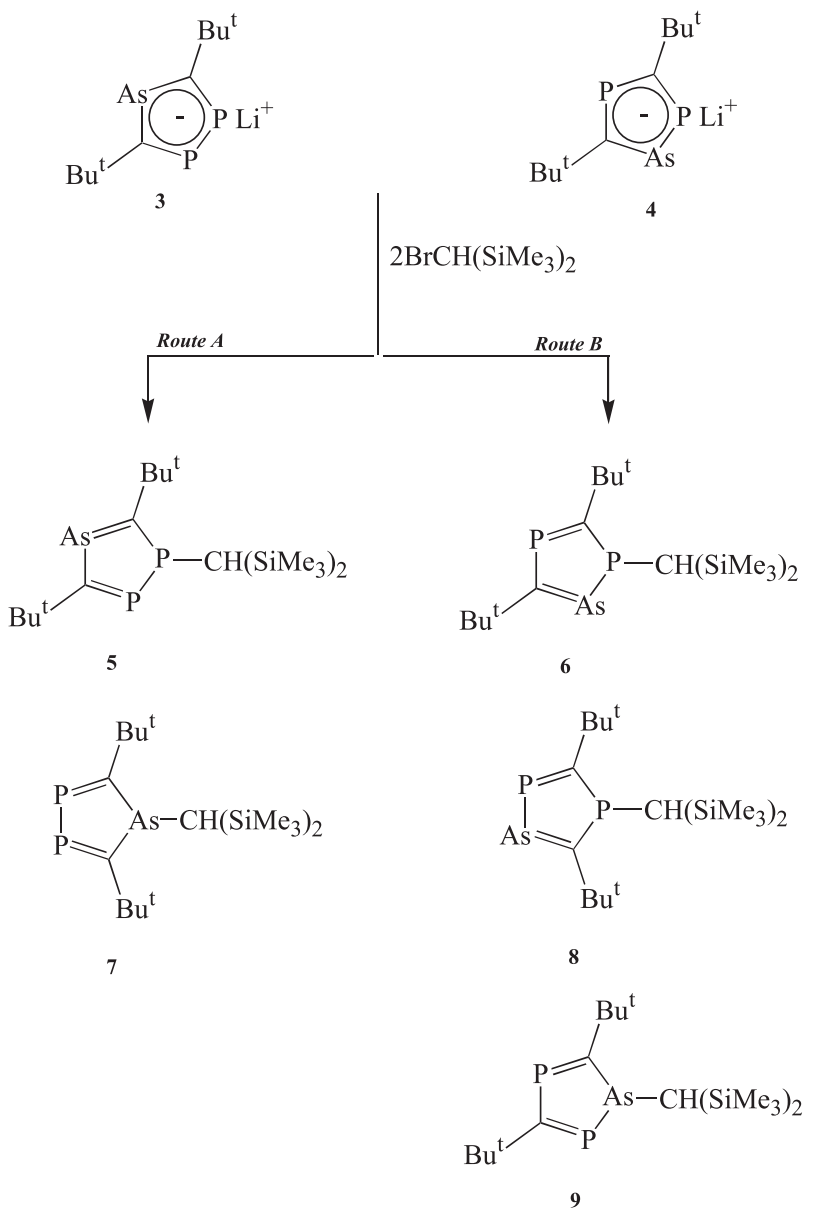

Figure 2. Preparation of the two arsadiphosphole 5 and $\mathbf{6}$

Figure 3 shows a ${ }^{31} \mathrm{P}\left\{{ }^{1} \mathrm{H}\right\}$ NMR spectrum of a mixture containing compounds $\mathbf{1}, \mathbf{5}$ and $\mathbf{6}$. The three doublets of 
doublets at $\delta 111.2,179.2$ and 243.7 easily identify compound $\mathbf{1}$, which has been completely characterized. ${ }^{10}$ The proposed structure for compound $\mathbf{5}$ (Figure 2) is based on this spectrum which shows the two phosphorus resonances at $\delta 106.8$ and 181.5 , which are typical for $\mathrm{sp}^{3}$ and $\mathrm{sp}^{2}$ hybridized phosphorus, respectively. Each signal appears as a doublet with a coupling constant ${ }^{1} J_{\mathrm{pp}}=523.6$ $\mathrm{Hz}$, typical for a direct P-P bond.

The spectrum in Figure 3 also shows the two phosphorus resonances for compound $\mathbf{6}$. These resonances appear at $\delta 132.2$ and 240.6 which are typical for $\mathrm{sp}^{3}$ and $\mathrm{sp}^{2}$ hybridized phosphorus, respectively. The coupling constant between the two phosphorus is $16.8 \mathrm{~Hz}$, and is typical for a two bonds coupling. These values, which are in complete agreement with the literature reports, ${ }^{14,15}$ support the proposed structure presented in Figure 2 where the $\mathrm{sp}^{3}$ phosphorus is bonded to the arsenic atom and the $\mathrm{sp}^{2}$ phosphorus lies between two carbon atoms. The synthesis of compounds $\mathbf{5}$ and $\mathbf{6}$ clearly shows that the R fragment bonds to the rings via the less stericaly hindered atoms, and it always occurs via one of two heteroatoms bonded together. The exclusive formation of compound 6 from the anionic ring $\mathbf{4}$ also shows the preference of the $\mathrm{R}$ group for the phosphorus atom. The relative stability of these isomers, generated from routes A and B, were investigated by ab initio calculations and also the inversion barrier about the $\mathrm{sp}^{3}$ heavy atom and the aromaticity character of each isomer will be discussed in the next sessions.

\section{Calculations}

The optimized MP2/6-31G(d) structural parameters for the five possible arsadiphosphole isomers generated in routes A and B (Figure 2) are shown in Figure 4 and the total energies, inversion barrier $\left(\Delta \mathrm{E}^{\#}\right)$ and relative stability $(\Delta \mathrm{E})$ are shown in Table 1.

As can be seen in Table 1, for all the five possible arsadiphosphole isomers there exist two possible structures for each isomer, corresponding to a planar and a nonplanar structures. The former corresponds to first-order saddle points on the potential energy surface, with respect to the out-of-plane bending about the phosphorus in isomers $\mathbf{A}$, $\mathbf{B}$ and $\mathbf{C}$ and out-of-plane bending about the arsenic in isomers $\mathbf{D}$ and $\mathbf{E}$. The planar forms of isomers $\mathbf{A}, \mathbf{B}, \mathbf{C}, \mathbf{D}$ and $\mathbf{E}$ have imaginary frequencies of 323i, 318i, 339i, $387 \mathrm{i}$ and $335 \mathrm{i} \mathrm{cm}^{-1}$ respectively. The nonplanar structures correspond to real minima on the potential energy surface. Analyzing the relative energy for the minimum structures found in routes $\mathrm{A}$ and $\mathrm{B}, \Delta \mathrm{E}$, quoted in Table 1 , it can be seen that isomer $\mathbf{A}$, analogous to $\mathbf{5}$, in which the phosphorus atom is in $\alpha$-position, is the most stable structure found in route A. Analogously, isomer $\mathbf{B}$, in which the arsenic atom is in $\alpha$-position, is the most stable structure obtained in
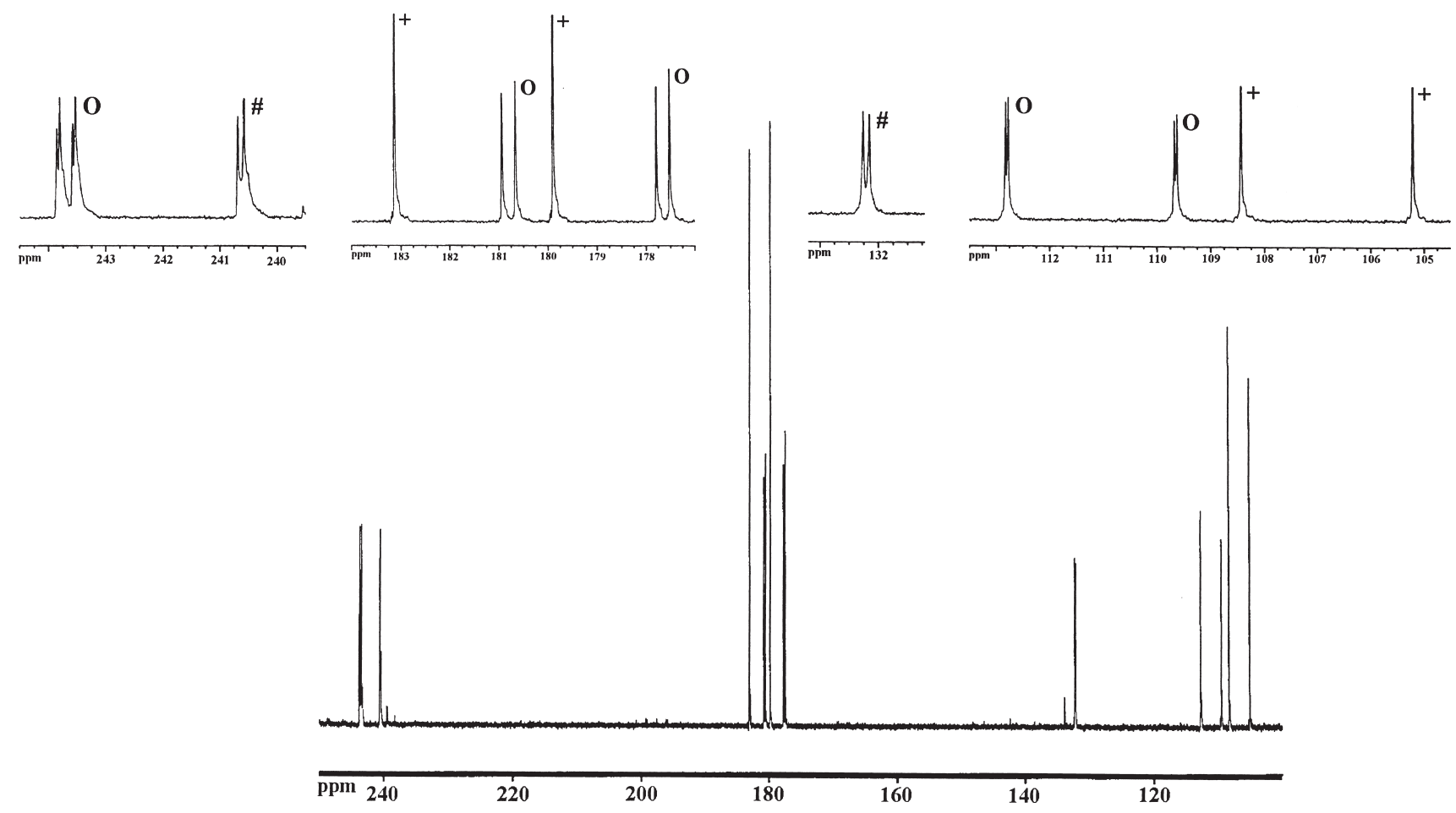

Figure 3. ${ }^{31} \mathrm{P}\left\{{ }^{1} \mathrm{H}\right\}$ NMR spectra of a mixture containing compound $\mathbf{1}(\mathbf{O})$, compound $\mathbf{5}(+)$ and compound $\mathbf{6}(\#)$ in chloroform- $\mathrm{d}_{1}$ at $25{ }^{\circ} \mathrm{C}$. 

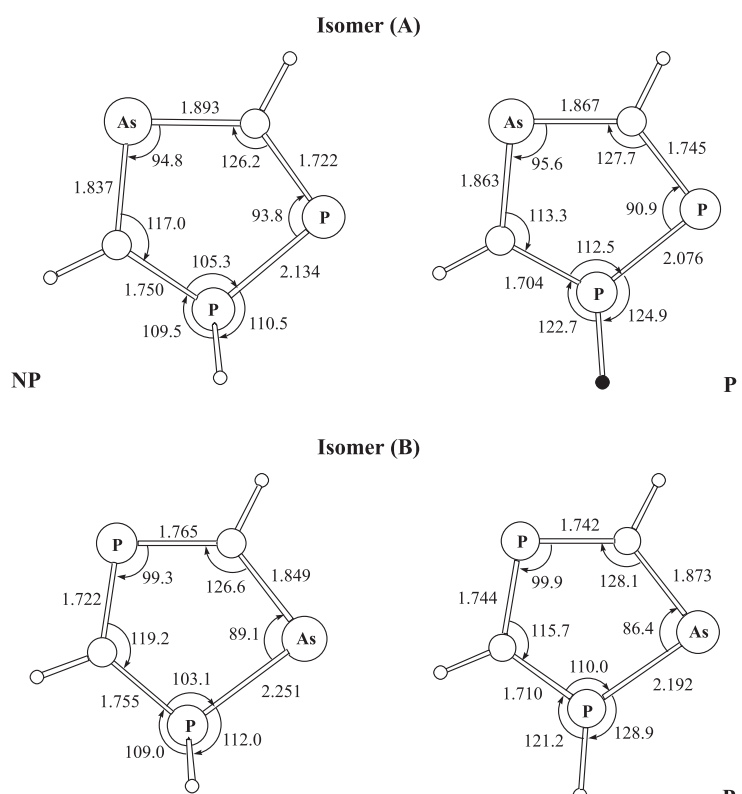

NP

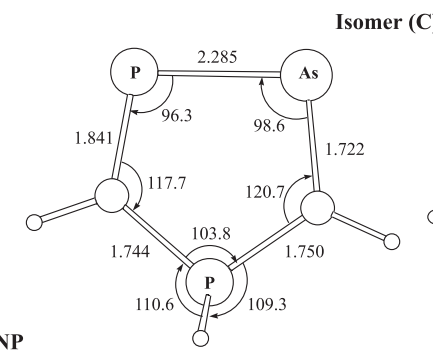

somer (C)

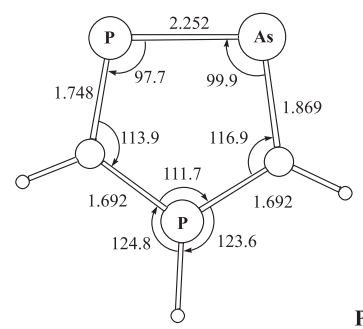

Isomer (D)

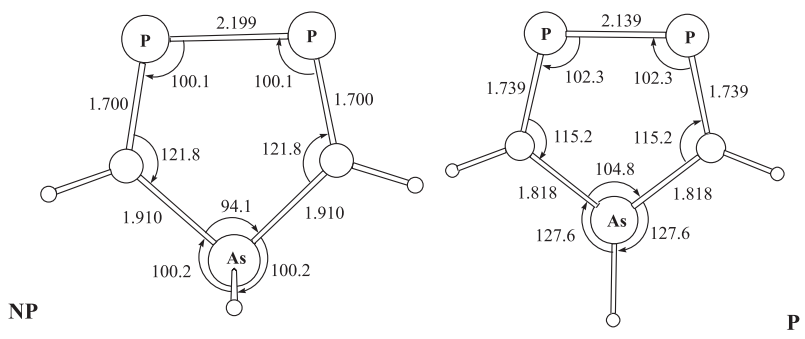

Isomer (E)
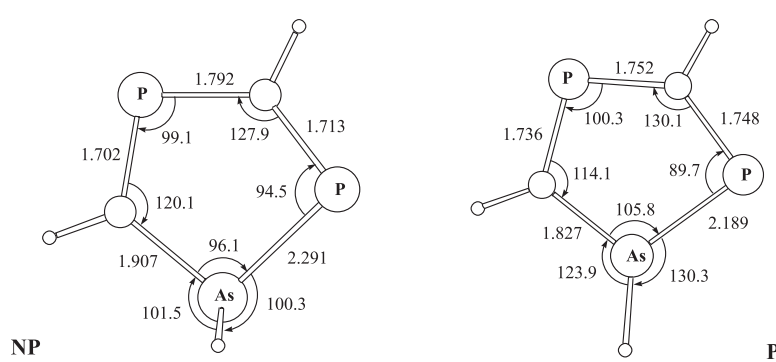

Figure 4. MP2/6-31G(d) Optimized structural parameters for the five possible arsadiphosphole isomers. $\mathbf{P}$ and NP stand for planar and non-planar forms, respectively. Bond lengths are given in $\AA$ and bond angles in degrees. route B. Using the computed MP2/6-31G(d) + ZPE relative energy for the minimum structures, we found a thermodynamic isomer distribution of $100 \%$ of isomer $\mathbf{A}$ in route A and $97.6 \%$ of isomer $\mathbf{B}, 2.0 \%$ of isomer $\mathbf{C}$ and $0.4 \%$ of isomer $\mathbf{E}$ in route B at $298.15 \mathrm{~K}$. The other isomer is present on a negligible percentage. This isomer distribution predicted theoretically for routes A and B is in complete agreement with the experimental finding in which only isomers $\mathbf{5}$ and $\mathbf{6}$, analogous to $\mathbf{A}$ and $\mathbf{B}$, respectively, were obtained in routes A and B. As we shall see later, the formation of isomers $\mathbf{5}$ and $\mathbf{6}$ is also connected with the aromatic character as well as with the energy barrier to pyramidal inversion around the phosphorus atom.

The pyramidal inversion barrier about phosphorus and arsenic atoms can also be seen in Table 1. For isomers $\mathbf{A}$ and $\mathbf{B}$, which are the most stable ones, found in routes $\mathrm{A}$ and $\mathrm{B}$, the inversion barriers computed at the MP2/6$31 \mathrm{G}(\mathrm{d})$ level of theory are $3.2 \mathrm{kcal} \mathrm{mol}^{-1}(1 \mathrm{kcal}=4.184$ $\mathrm{kJ})$. The inversion barriers about arsenic are much higher, exhibiting the values of 11.1 and $8.6 \mathrm{kcal} \mathrm{mol}^{-1}$ for isomers $\mathbf{D}$ and $\mathbf{E}$ respectively. Previous theoretical work on triphospholes ${ }^{9}$ has shown that the inversion barriers about phosphorus are 2.0 and $1.7 \mathrm{kcal} \mathrm{mol}^{-1}$ for $1,2,5$ - and 1,2,4triphospholes respectively, at the MP2/6-311G(2d)//MP2/ 6-31G(d) level and 3.7 and $4.4 \mathrm{kcal} \mathrm{mol}^{-1}$ respectively at the CCSD(T)/6-311G(2d)//MP2/6-31G(d) level of theory. This fact shows that the introduction of an arsenic atom on the five membered ring has little effect in the inversion barrier about the phosphorus, as compared with the analogous triphospholes. Similarly to the case of phosphole and triphospholes, ${ }^{9}$ the inversion barriers for the arsadiphosphole isomers are larger at the HF than at the MP2 level, indicating that electron correlation plays an important role in obtaining inversion barriers. As in the case of triphospholes, the inversion barriers about phosphorus in the arsadiphospholes are drastically reduced when compared with the values found for phosphole itself. For instance, Egan et al..$^{16,17}$ demonstrated by variable temperature NMR studies that the barrier to pyramidal inversion at phosphorus in 1-isopropyl-2-methyl-5phenylphosphole has the value of $16 \mathrm{kcal} \mathrm{mol}^{-1}$. Recent $a b$ initio results have shown that, at the $\mathrm{HF} / 6-311 \mathrm{G}(\mathrm{d})^{18}$ and MP2/6-31G(d), ${ }^{9}$ the pyramidal inversion barrier in phosphole is 24 and $17 \mathrm{kcal} \mathrm{mol}^{-1}$, respectively. Compared with our value of $3.2 \mathrm{kcal} \mathrm{mol}^{-1}$ found for the pyramidal inversion barrier in isomers $\mathbf{A}$ and $\mathbf{B}$, the value of $17 \mathrm{kcal}$ mol $^{-1}$ obtained for phosphole, at the same level of theory, is $13.8 \mathrm{kcal} \mathrm{mol}^{-1}$ higher, which shows that the introduction of one phosphorus and an arsenic atoms in the five membered ring reduces the inversion barrier about the phosphorus by $81 \%$. 
Table 1. Gas phase parameters for the investigated compounds at the MP2/6-31G(d) level of theory

\begin{tabular}{|c|c|c|c|c|c|c|c|c|c|c|}
\hline & \multicolumn{4}{|c|}{ Route A } & \multicolumn{6}{|c|}{ Route B } \\
\hline & \multicolumn{2}{|c|}{ Isomer A } & \multicolumn{2}{|c|}{ Isomer D } & \multicolumn{2}{|c|}{ Isomer B } & \multicolumn{2}{|c|}{ Isomer C } & \multicolumn{2}{|c|}{ Isomer E } \\
\hline & Planar & Nonpl. & Planar & Nonpl. & Planar & Nonpl. & Planar & Nonpl. & Planar & Nonpl. \\
\hline$-\mathrm{E}_{\mathrm{Tot}}{ }^{\mathrm{a}}$ & 2991. & 33500 & 2991. & 71760 & 2991. & 92235 & 2991. & 38484 & 2991. & 36343 \\
\hline $\mathrm{ZPE}^{\mathrm{b}}$ & 0.043071 & 0.043515 & 0.042097 & 0.042635 & 0.043218 & 0.043559 & 0.043188 & 0.043512 & 0.042415 & 0.042815 \\
\hline$v^{\mathrm{c}}$ & -323 & & -387 & & -318 & & -339 & & -335 & \\
\hline$\Delta \mathrm{E}^{\# \mathrm{~d}}$ & $\begin{array}{c}3.2 \\
(5.7)\end{array}$ & & $\begin{array}{c}11.1 \\
(19.7)\end{array}$ & & $\begin{array}{c}3.2 \\
(5.1)\end{array}$ & & $\begin{array}{c}3.2 \\
(6.1)\end{array}$ & & $\begin{array}{c}8.6 \\
(15.3)\end{array}$ & \\
\hline$\Delta \mathrm{E}^{\mathrm{e}}$ & & 0 & & 6.8 & & 0 & & 2.3 & & 3.2 \\
\hline $\mathrm{NICS}^{\mathrm{f}}$ & -16.1 & -10.7 & -16.8 & -5.8 & -16.3 & -10.8 & -16.1 & -10.0 & -16.5 & -7.4 \\
\hline
\end{tabular}

${ }^{\mathrm{a}}$ Total energy for the non-planar structure in a.u. ${ }^{\mathrm{b}}$ Zero Point Vibrational Energy in a.u. ${ }^{\mathrm{c}}$ Negative eigenvalue in the hessian matrix in $\mathrm{cm}^{-1}$. ${ }^{\mathrm{d}} \mathrm{MP} 2 / 6-31 \mathrm{G}(\mathrm{d})+\mathrm{ZPE}$ inversion barrier in $\mathrm{kcal} \mathrm{mol}^{-1}(1 \mathrm{kcal}=4.184 \mathrm{~kJ}), \mathrm{HF} / 6-31 \mathrm{G}(\mathrm{d})+\mathrm{ZPE}$ barriers in parenthesis. ${ }^{\mathrm{e}} \mathrm{MP} 2 / 6-31 \mathrm{G}(\mathrm{d})+\mathrm{ZPE}$ relative energy for the minimum structures in $\mathrm{kcal} \mathrm{mol}^{-1} .{ }^{\mathrm{f}}$ Nucleus-Independent Chemical Shift at the ring center in ppm.

\section{Aromaticity of the arsadiphospholes}

Since the synthesis of the first five membered rings containing phosphorus, phosphole, the key issue concerning these heterocyclic ring systems was their potential aromaticity. Mathey and co-workers ${ }^{20}$ using photoelectron spectroscopy and Mislow and co-workers ${ }^{21}$ studying NMR spectroscopy were the first to consider the aromaticity of phosphole, comparing the inversion barrier around phosphorus of alkyl-substituted phospholes with phospholanes (the saturated analogue of phosphole). It is important to mention that the concept of aromaticity is dependent upon the criteria employed to measure it, i. $e$. molecular structure, chemical reactivity, and UV spectroscopy. As a result, several quantitative criteria for aromaticity are known. ${ }^{21}$ The most widely used are energetic (aromatic stabilization energies, ASE), ${ }^{22}$ structural (nearly equal bond lengths in the ring), ${ }^{23}$ and magnetic properties such as magnetic susceptibilities. ${ }^{24}$ Nevertheless, in the particular case of phosphole, it requires a flat ring with the electron lone pair on the phosphorus atom highly delocalized. ${ }^{3}$ Recently, Schleyer and co-workers ${ }^{25}$ proposed the use of absolute magnetic shieldings, computed at ring centers, as a criterion to measure the aromatic character of cyclic structures, referred to as NICS (Nucleus-Independent Chemical Shifts). Negative NICS values denote aromaticity whereas small and positive NICS values indicate nonaromaticity. It was shown that the NICS correlates with other aromaticity indexes as ASE, magnetic susceptibility exaltations and with structural variations, establishing NICS as a consistent aromaticity probe. ${ }^{25}$ The NICS have been applied recently to study the aromaticity of poly- phosphaphospholes, ${ }^{26}$ showing that the aromaticity decreases with the piramidality of the tricoordinate phosphorus.

We have applied the NICS index to the arsadiphospholes. The NICS values obtained for the five arsadiphosphole isomers are quoted in Table 1. As it can be seen, the aromatic index obtained for the nonplanar forms of isomers $\mathbf{A}, \mathbf{B}$ and $\mathbf{C}$, in which the R group bonds to the phosphorus atom, are $-10.7,-10.8$ and -10.0 , respectively, and -5.8 and -7.4 , respectively for the nonplanar forms of isomers $\mathbf{D}$ and $\mathbf{E}$, in which the R group bonds to arsenic. It is interesting to see that the aromatic character is directly connected with the energy barrier for pyramidal inversion. Isomers $\mathbf{D}$ and $\mathbf{E}$ have larger values for pyramidal inversion (Table 1), so the aromaticity character decreases as compared with isomers $\mathbf{A}, \mathbf{B}$ and $\mathbf{C}$. The combination of high energy barrier and low aromaticity found for isomers $\mathbf{D}$ and $\mathbf{E}$ explains why the $\mathbf{R}$ group bonds preferentially to the phosphorus atoms in the synthesis of the arsadiphospholes (Figure 2), in which the resulting structures are more aromatic. However, it should be said that inversion barriers are inherently greater at As centers than at $\mathrm{P}$ centers, even for simple systems like $\mathrm{PH}_{3}$ and $\mathrm{AsH}_{3}$. So, larger inversion barriers at As cannot necessarily be connected to aromaticity. The most stable structures found in routes A and B, A and $\mathbf{B}$, respectively have almost the same aromaticity index. To have a reference point, the computed NICS values for the well known aromatic five membered rings pyrrole, thiophene and furan are $-17.3,-14.7$ and -13.9 respectively, at the same level..$^{25}$ The NICS value of -5.9 computed for phosphole, is almost half the value of -11.5 computed for benzene, justifying 
its non-aromatic character. In fact, some authors ${ }^{27}$ arbitrarily assign the convention that if the molecule has less than half the magnitude of the NICS value in comparison to that of benzene, it is not aromatic. Comparing with phosphole it can be concluded from these results that, the inclusion of another phosphorus and an arsenic atom in the five membered rings reduces the energy barrier for the pyramidal inversion about the phosphorus and, the most stable structures $\mathbf{A}$ and $\mathbf{B}$, analogous to the synthesized ones, show some aromatic character.

\section{The effect of the bulky substituent}

All the calculations reported so far on the arsadiphosphole isomers were carried out for model compounds, that is, all substituent groups were replaced by hydrogen atoms. In order to see the effects of real substituents on the aromaticity character and energy barriers, we performed the same calculations on the most stable isomers $\mathbf{A}$ and $\mathbf{B}$, found in routes $\mathrm{A}$ and $\mathrm{B}$, using a more realistic bulky substituent $\mathrm{CH}\left(\mathrm{SiH}_{3}\right)_{2}$. To make it clear, we will refer to the structures generated by the introduction of the bulky $\mathrm{R}$ group as $\mathbf{A}^{\prime}$ and $\mathbf{B}$ '. The optimized MP2/6-31G(d) parameters for structures $\mathbf{A}^{\prime}$ and $\mathbf{B}^{\prime}$ are shown in Figure 5 and the total energies, inversion barriers and NICS values are reported in Table 2. As it can be seen in Table 2, the introduction of the $\mathrm{CH}\left(\mathrm{SiH}_{3}\right)_{2}$ group reduces the pyramidal inversion barrier about the phosphorus to 1.3 and $1.2 \mathrm{kcal}$ $\mathrm{mol}^{-1}$ in isomers A' and $\mathbf{B}$ ' respectively, which corresponds to a reduction of $58 \%$ and $63 \%$ as compared with values computed for $\mathbf{A}$ and $\mathbf{B}$. These results agree with the findings of Cloke and co-workers who have shown that the bulky substituent $\mathrm{SiMe}_{3}$ can indeed induce planarity in the ring structure of triphospholes. ${ }^{11}$ The reduction in the energy barrier will result in more aromatic structures, as can be seen from the NICS values reported in Table 2, for the nonplanar forms of A' and $\mathbf{B}$ '. The NICS values of -15.1 and

Table 2. Gas phase parameters for the compounds A' and B', with bulky substituents, computed at the MP2/6-31G(d) level of theory

\begin{tabular}{|c|c|c|c|c|}
\hline & $\begin{array}{r}\mathbf{R}=C^{\prime} \\
\text { Isol }\end{array}$ & $\left(\mathrm{SiH}_{3}\right)_{2}$ & $\begin{array}{r}\mathbf{R}=\mathrm{C} \\
\text { Isom }\end{array}$ & $\left(\mathrm{SiH}_{3}\right)_{2}$ \\
\hline & Planar & Nonpl. & Planar & Nonpl. \\
\hline$-\mathrm{E}_{\text {Tot. }}{ }^{\mathrm{a}}$ & 3610 & 73729 & 3610. & 2577 \\
\hline $\mathrm{ZPE}^{\mathrm{b}}$ & 0.105147 & 0.105672 & 0.105659 & 0.105831 \\
\hline$v^{\mathrm{c}}$ & -63.4 & - & -83.1 & - \\
\hline$\Delta \mathrm{E}^{\# \mathrm{~d}}$ & & 1.34 (1.64) & $1.20(1.07)$ & \\
\hline $\mathrm{NICS}^{\mathrm{e}}$ & -11.6 & -15.1 & -12.2 & -15.3 \\
\hline
\end{tabular}

a Total energy for the non-planar structure in a.u. ${ }^{\mathrm{b}}$ Zero Point Vibrational Energy in a.u. ${ }^{c}$ Negative eigenvalue in the hessian matrix in $\mathrm{cm}^{-1} .{ }^{\mathrm{d}} \mathrm{MP} 2 / 6-31 \mathrm{G}(\mathrm{d})+\mathrm{ZPE}$ inversion barrier in $\mathrm{kcal} \mathrm{mol}^{-1}(1 \mathrm{kcal}=$ 4.184kJ), HF/6-31G(d) + ZPE barriers in parenthesis. ${ }^{e}$ Nucleus Independent Chemical Shift at the ring center in ppm.

Isomer (A')

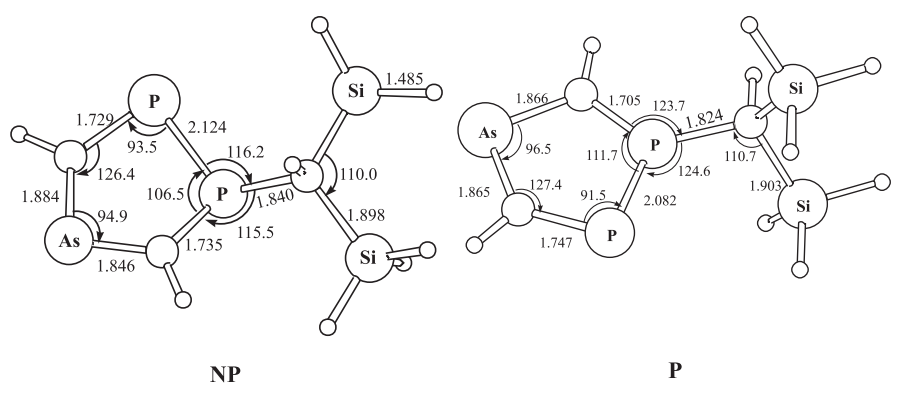

Isomer (B')

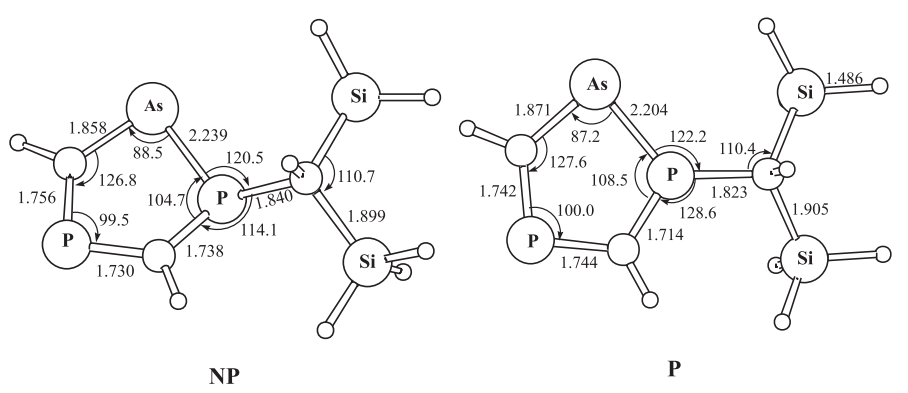

Figure 5. MP2/6-31G(d) Optimized structural parameters for the most stable isomers found in routes A and B, using a more realistic bulky group $\mathrm{CH}\left(\mathrm{SiH}_{3}\right)_{2}$. $\mathbf{P}$ and NP stand for planar and non-planar forms, respectively. Bond lengths are given in $\AA$ and bond angles in degrees. 
-15.3 for isomers A' and $\mathbf{B}^{\prime}$ 'respectively, corresponds to an increase of $42 \%$ in aromatic character as compared with the values computed for $\mathbf{A}$ and $\mathbf{B}$, which clearly shows the connection between the reduction in the energy barrier and the aromatic character. It is important to mention that the MP2/6-31G(d) optimized structures for the planar forms of A' and B' still have one imaginary frequency, meaning that these structures are first order saddle points, with small negative eigenvalue on the hessian matrices (see Table 2). However, the main contribution to these normal modes comes from the $\mathrm{SiH}_{3}$ rotation, with a small contribution from the out-of-plane bending about the phosphorus.

The comparison of the bond angles around the phosphorus obtained for the isomers A' and $\mathbf{B}$ ', with the Xray results obtained for mono, di and triphospholes is shown in Table 3. As can be seen, the summation of the bond angles in isomers $\mathbf{A}^{\prime}$ and $\mathbf{B}$ ' is larger than the experimental values found for mono and diphosphole and almost the same found for triphosphole, with the differences being 35.5, 18.2 and $4.1^{\circ}$, respectively, for isomer $\mathbf{A}^{\prime}$ and $36.5,19.3$ and $3.0^{\circ}$ for isomer B'. We do believe that the bond angle summation around the phosphorus could be even closer to $360^{\circ}$ if the real ligands used in the synthesis were employed.

\section{Experimental}

All manipulations were carried out under an atmosphere of dry nitrogen gas or argon using high-vacuum line techniques with glassware that had previously been flamedried. Solvents were rigorously dried and redistilled before use. The arsine $\mathrm{As}\left(\mathrm{SiMe}_{3}\right)_{3}$ was synthesized by a published route. $^{30}$ The $c a .0 .08 \mathrm{~mol} \mathrm{~L}^{-1} \mathrm{DME}$ solution containing both $\mathrm{LiAsP}{ }_{2} \mathrm{C}_{2} \mathrm{Bu}_{2}^{\mathrm{t}}$ rings $\mathbf{3}$ and $\mathbf{4}$ was prepared from $\mathrm{As}\left(\mathrm{SiMe}_{3}\right)_{3}$ and $\mathrm{Me}_{3} \mathrm{SiP}=\mathrm{C}\left(\mathrm{OSiMe}_{3}\right) \mathrm{Bu}^{\mathrm{t}}$, using a method described by Nixon and co-workers. ${ }^{31}$ The ${ }^{31} \mathrm{P}$ NMR spectra were recorded on a Bruker DRX 400 spectrometer at 161.9 $\mathrm{MHz}$ using $\mathrm{H}_{3} \mathrm{PO}_{4}(85 \%)$ as external reference.
Synthesis of $\left(\mathrm{AsP}_{2} \mathrm{C}_{2} \mathrm{Bu}{ }_{2}\right) \mathrm{CH}\left(\mathrm{SiMe}_{3}\right)_{2}$ : isomers 5 and $\mathbf{6}$

To $15 \mathrm{~mL}$ of a DME solution containing both $\mathrm{LiAsP}_{2} \mathrm{C}_{2} \mathrm{Bu}_{2}^{\mathrm{t}}$ rings $\mathbf{3}$ and $\mathbf{4}$ (1.20 mmol of each isomer), at $-40{ }^{\circ} \mathrm{C}$, was slowly added a solution of $0.60 \mathrm{~mL}$ of $\mathrm{BrCH}\left(\mathrm{SiMe}_{3}\right)_{2}(2.50 \mathrm{mmol})$ dissolved in DME $(15.0 \mathrm{~mL})$. The resulting mixture was warmed to room temperature and stirred for $24 \mathrm{~h}$. The volatiles were removed in vacuum and the brown oily residue was purified by chromatographic column (kieselgel/b.p. 60-80 ${ }^{\circ} \mathrm{C}$ ). An unique fraction containing both rings $(0.65 \mathrm{~g})$ was isolated and the isomers were characterized by ${ }^{31} \mathrm{P}$ NMR spectroscopy.

${ }^{31} \mathrm{P}$ NMR data for compounds 5 and 6. 5: ${ }^{31} \mathrm{P}\left\{{ }^{1} \mathrm{H}\right\}$ NMR d 106.8 (d), 181.5 (d) $\left({ }^{1} \mathrm{~J}_{\mathrm{P}(\mathrm{A}) \mathrm{P}(\mathrm{B})} 523.6 \mathrm{~Hz}\right) .6:{ }^{31} \mathrm{P}\left\{{ }^{1} \mathrm{H}\right\} \mathrm{NMR}$ d $132.2(\mathrm{~d}), 240.6$ (d) $\left({ }^{2} \mathrm{~J}_{\mathrm{P}(\mathrm{A}) \mathrm{P}(\mathrm{B})} 16.8 \mathrm{~Hz}\right)$.

\section{Theoretical details}

$A b$ initio molecular orbital calculations were performed for the five possible arsadiphosphole isomers 5, 6, 7, 8 and $\mathbf{9}$, in which the bulky substituents were all replaced by hydrogen atoms. These model systems will be referred to as isomers $\mathbf{A}, \mathbf{B}, \mathbf{C}, \mathbf{D}$ and $\mathbf{E}$, respectively, hereafter.

Full geometry optimizations were performed at the second-order Møller-Plesset perturbation (MP2) level of theory, without any symmetry constraint, using the splitvalence basis set 6-31G(d), ${ }^{32,33}$ which includes a set of five $\mathrm{d}$ polarization functions on the heavy atoms. Previous theoretical work on phosphole ${ }^{9}$ showed that the MP2/6$31 \mathrm{G}(\mathrm{d})$ level gives a rather accurate description (compared to higher correlated levels) of the inversion barrier and aromaticity effects in the case of phosphole, which justify the use of this level of theory in this work. The stationary points located on the Potential Energy Surface (PES) were characterized by calculating the hessian matrices at the MP2/6-31G(d) level, where the minimum energy structures

Table 3. X-ray structural data for mono- di- and triphospholes and MP2/6-31G(d) results for isomers A' and B' of arsadiphosphole*

\begin{tabular}{|c|c|c|c|c|c|}
\hline $\mathbf{R}$ & $\left(\mathbf{R}=\mathrm{CH}_{2} \mathrm{Ph}\right)^{28}$ & $\left(\mathbf{R}=\mathrm{P}_{2} \mathrm{C}_{3} \mathrm{Bu}_{3}^{\mathrm{t}}\right)^{29}$ & $\left(\mathbf{R}=\mathrm{CH}\left(\mathrm{SiMe}_{3}\right)_{2}\right)^{10}$ & $\begin{array}{c}\mathbf{R}=\mathrm{CH}\left(\mathrm{SiH}_{3}\right)_{2} \\
\text { Isomer }\left(\mathbf{A}^{\prime}\right)\end{array}$ & $\begin{array}{c}\mathbf{R} \\
\mathbf{R}=\mathrm{CH}\left(\mathrm{SiH}_{3}\right)_{2} \\
\text { Isomer }\left(\mathbf{B}^{\prime}\right)\end{array}$ \\
\hline$\alpha$ & $90.7(2)$ & $99.7(2)$ & $105.8(1)$ & 106.5 & 104.7 \\
\hline$\beta$ & $105.9(2)$ & $107.2(2)$ & $115.3(1)$ & 115.5 & 114.1 \\
\hline$\delta$ & $106.1(2)$ & $113.1(2)$ & $121.2(2)$ & 116.2 & 120.5 \\
\hline$\sum(\alpha+\beta+\delta)$ & 302.7 & 320.0 & 342.3 & 338.2 & 339.3 \\
\hline
\end{tabular}

* Bond angles, as indicated at the top of the Table, are given in degrees 
have no imaginary frequency, and the first order transition state structures have one imaginary frequency. The Nucleus Independent Chemical Shift (NICS) approach was applied to all forms of the arsadiphosphole isomers. Absolute NMR shieldings were calculated using the GIAO method ${ }^{34}$ at the MP2/6-31G(d) level. NICS values were obtained by calculating the absolute NMR shieldings at the geometrical ring centers (non-weighted mean of the heavy atom coordinates). All calculations reported here were done using the Gaussian98 program package. ${ }^{35}$

\section{Conclusions}

In this work we have presented the synthesis of two arsadiphospholes, which are five membered rings containing two phosphorus and an arsenic atom forming the ring structure. We found that the mixture containing both rings 3 and 4 reacts with $\mathrm{BrCH}\left(\mathrm{SiMe}_{3}\right)_{2}$ in dimethoxyethane to give exclusively the two new arsadiphospholes $\mathbf{5}$ and $\mathbf{6}$, which have both been characterized by ${ }^{31} \mathrm{P} \mathrm{NMR}$. Ab initio molecular orbital calculations were performed at the MP2/ 6-31G(d) level of theory to evaluate the relative stability, inversion barrier and aromaticity character of the five possible arsadiphosphole isomers. The computed relative stability of the arsadiphosphole isomers in gas phase is in complete agreement with the experimental findings. The energy barrier to pyramidal inversion calculated for isomers $\mathbf{A}$ and $\mathbf{B}$ (analogues of the experimentally obtained $\mathbf{5}$ and $\mathbf{6}$ ) was 3.5 and $3.4 \mathrm{kcal} \mathrm{mol}^{-1}$. Applying the Nucleus Independent Chemical Shift approach, we showed that the inclusion of two phosphorus and an arsenic atom in the five membered rings reduces the energy barrier for pyramidal inversion and the resulting structures are aromatic. The combination of high energy barrier and low aromaticity found for isomers $\mathbf{D}$ and $\mathbf{E}$ explains why the R group bonds preferentially to the phosphorus atoms in the synthesis of the arsadiphospholes. We have also shown by means of theoretical calculations that the structures generated by introducing the more realistic $\mathrm{CH}\left(\mathrm{SiH}_{3}\right)_{2}$ bulky group are more planar, with a very small energy barrier to pyramidal inversion about the phosphorus. Studies of the coordination chemistry and reactivity of the arsadiphospholes are underway and will be described in future publications.

\section{Acknowledgments}

The authors would like to thank CNPq (Conselho Nacional de Desenvolvimento Científico e Tecnológico) and PIBIC-FAPEMIG (Fundação de Amparo à Pesquisa do Estado de Minas Gerais) for research grants and PrPqUFMG (Pró-Reitoria de Pesquisa da Universidade Federal de Minas Gerais) for financial support. The CENAPADMG/CO-NAR (UFJF) (Centro Nacional de Processamento de Alto Desempenho de Minas Gerais e Região CentroOeste) is also thanked for the computational resources.

\section{References}

1. Leavitt, F. C.; Manuel, T. A.; Johnson, F.; J. Am. Chem. Soc. 1959, 81, 3163.

2. Mathey, F.; Chem. Rev. 1988, 88, 437.

3. Mathey, F.; J. Organomet. Chem. 1990, 400, 400.

4. Caliman, V.; Quím. Nova. 2000, 23, 346.

5. Schleyer, P. v. R.; Freeman, P. K.; Jiao H.; Goldfuss B.; Angew. Chem., Int. Ed. Engl. 1995, 34, 337.

6. Kutzelning, W.; Angew. Chem., Int. Ed. Engl. 1984, 213, 272.

7. Nyulászi, L.; Várnai, P.; Veszprémi, T.; J. Mol. Struct. (THEOCHEM). 1995, 358, 55.

8. Nyulászi, L.; J. Phys. Chem. 1995, 99, 586.

9. Nyulászi, L.; J. Phys. Chem. 1996, 100, 6194.

10. Caliman, V.; Hitchcock, P. B.; Nixon, J. F.; J. Chem. Soc., Chem. Commun. 1995, 1661.

11. Cloke, F. G. N.; Hitchcock, P. B.; Hunnable, P.; Nixon, J. F.; Nyulászi, L.; Nieche, E.; Thelen, V.; Angew. Chem., Int. Ed. Engl. 1998, 37, 1083.

12. Bird, C. W.; Tetrahedron 1985, 41, 1409.

13. Bartsch, R.; Hitchcock, P. B.; Johnson, J. A.; Matos, R. M.; Nixon, J. F.; Phosphorus Sulfur 1993, 77, 45.

14. Geissler, B.; Barth, S.; Bergsträsser, U.; Slany, M.; Durkin, J.; Hitchcock, P. B.; Hofmann, M.; Binger, P.; Nixon, J. F.; Schleyer, P. v. R.; Regitz, M.; Angew. Chem., Int. Ed. Engl. 1995, 34, 484.

15. Caliman, V.; Hitchcock, P. B.; Nixon, J. F.; Chem. Commun. 1997, 1739.

16. Egan, W.; Tang, R.; Zon, G.; Mislow, K.; J. Am. Chem. Soc. 1970, 92, 1442.

17. Egan, W., Tang, R.; Zon, G.; Mislow, K.; J. Am. Chem. Soc. 1971, 93, 6205.

18. Hughes, A. N.; Edscombe, K. E.; Heterocycles 1992, 33, 563.

19. Schäfer, W; Schweig, A; Märkl, G; Hauptmann, H; Mathey, F.; Angew. Chem., Int. Ed. Engl. 1973, 12, 145.

20. Andose, J. D.; Rauk, A.; Mislow, K.; J. Am. Chem. Soc. 1974, 96, 6904.

21. Schleyer, P. v. R.; Chem. Rev. 2001, 101 (Special Thematic Issue on Aromaticity).

22. Dewar, M. J. S.; De Llano, C.; J. Am. Chem. Soc. 1969, 91, 789. Aihara, J.; J. Chem. Soc., Perkin Trans. 2 1996, 2185.

23. Aihara, J.; J. Org. Chem. 1976, 41, 2488.

24. Benson, R. C.; Flygare, W. H.; J. Am. Chem. Soc. 1970, 92, 7593.

25. Schleyer, P. v. R.; Maeker, C.; Dransfeld, A.; Jiao, H.; Hommes, N. v. E.; J. Am. Chem. Soc. 1996, 118, 6317. 
26. Dransfeld, A.; Nyulászi, L.; Schleyer, P. v. R.; Inorg. Chem. 1998, 37, 4413.

27. Jemmis, E. D.; Kiran, B.; Inorg. Chem. 1998, 37, 2110. Quiñonero, D.; Frontera, A.; Ballester, P.; Deyà, P. M.; Tetrahedron Lett. 2000, 41, 2001.

28. Coggon, P.; McPhail, A. T.; J. Chem. Soc., Dalton Trans. 1993, 1888.

29. Al-Juaid, S. S.; Hitchcock, P. B.; Matos, R. M.; Nixon, J. F.; J. Chem. Soc., Chem. Commun. 1993, 267.

30. Becker, G.; Gutekunst, G.; Wessely, H. J.; Z. Anorg. Allg. Chem. 1980, 462, 113.

31. Al-Juaid, S. S.; Hitchcock, P. B.; Johnson, J. A.; Nixon, J. F.; J. Organomet. Chem., 1994, 480, 45.

32. Ditchfield, R.; Hehre, W. J.; Pople, J. A.; J. Chem. Phys. 1971, $54,724$.

33. Hehre, W. J.; Ditchfield, R.; Pople, J. A.; J. Chem. Phys. 1972, 56, 2257.

34. Wolinski, K.; Hinto, J. F.; Pulay, P.; J. Am. Chem. Soc. 1990 , $112,8251$.
35. Gaussian 98, Revision A.6. Frisch, M. J.; Trucks, G. W.; Schlegel, H. B.; Scuseria, G. E.; Robb, M. A.; Cheeseman, J. R.; Zakrzewski, V. G.; Montgomery, Jr., J. A.; Stratmann, R. E.; Burant, J. C.; Dapprich, S.; Millam, J. M.; Daniels, A. D.; Kudin, K. N.; Strain, M. C.; Farkas, O.; Tomasi, J.; Barone, V.; Cossi, M.; Cammi, R.; Mennucci, B.; Pomelli, C.; Adamo, C.; Clifford, S.; Ochterski, J.; Petersson, G. A.; Ayala, P. Y.; Cui, Q.; Morokuma, K.; Malick, D. K.; Rabuck, A. D.; Raghavachari, K.; Foresman, J. B.; Cioslowski, J.; Ortiz,J. V.; Stefanov, B. B.; Liu, G.; Liashenko, A.; Piskorz, P.; Komaromi, I.; Gomperts,R.; Martin, R. L.; Fox, D. J.; Keith, T.; Al-Laham, M. A.; Peng, C. Y.; Nanayakkara, A.; Gonzalez, C.; Challacombe, M.; Gill, P. M. W.; Johnson, B.; Chen, W.; Wong, M. W.; Andres, J. L.; Head-Gordon, M.; Replogle, E. S.; Pople, J. A. Gaussian, Inc., Pittsburgh PA, 1998.

Received: September 14, 2001 Published on the web: July 16, 2002 